Research Paper

\title{
Pattern of distant extrahepatic metastases in primary liver cancer: a SEER based study
}

\author{
Wenrui $\mathrm{Wu}^{1,2^{*}}$, Xingkang $\mathrm{He}^{3^{*}}$, Dewi Andayani ${ }^{1,2^{*}}$, Liya Yang ${ }^{1,2}$, Jianzhong $\mathrm{Ye}^{1,2}$, Yating $\mathrm{Li}^{1,2}$, Yanfei Chen ${ }^{1,2}$, \\ Lanjuan $\mathrm{Li}^{1,2, \otimes}$ \\ 1. State Key Laboratory for Diagnosis and Treatment of Infectious Diseases, The First Affiliated Hospital, School of Medicine, Zhejiang University, Hangzhou, \\ China \\ 2. Collaborative Innovation Center for Diagnosis and Treatment of Infectious Diseases, Hangzhou, China \\ 3. Department of Gastroenterology, Sir Run Run Shaw Hospital, Zhejiang University Medical School, Hangzhou 310016, China \\ *Authors contributed equally to this work. \\ $\square$ Corresponding author: State Key Laboratory for Diagnosis and Treatment of Infectious Disease, The First Affiliated Hospital, College of Medicine, Zhejiang \\ University, Hangzhou 310003, P. R. China. Tel.: +86-571-8723-6458; Fax: +86-571-8723-6459; E-mail: lji@@zju.edu.cn. \\ () Ivyspring International Publisher. This is an open access article distributed under the terms of the Creative Commons Attribution (CC BY-NC) license \\ (https://creativecommons.org/licenses/by-nc/4.0/). See http://ivyspring.com/terms for full terms and conditions.
}

Received: 2017.01.04; Accepted: 2017.05.02; Published: 2017.07.21

\begin{abstract}
Background and Aims: Primary liver cancer remains still the common cause of cancer-related deaths globally and the prognosis for patients with extrahepatic metastasis is poor. The aim of our study was to assess extrahepatic metastatic pattern of different histological subtypes and evaluate prognostic effects of extrahepatic metastasis in patients with advanced disease.

Methods: Based on the Surveillance, Epidemiology and End Results (SEER) database, eligible patients diagnosed with primary liver cancer was identified between 2010 to 2012. We adopted Chi-square test to compared metastasis distribution among different histological types. We compared survival difference of patients with different extrahepatic metastasises by Kaplan-Meier analysis. Cox proportional hazard models were performed to identify other prognostic factors of overall survival.

Results: We finally identified 8677 patients who were diagnosed with primary liver cancer from 2010 to 2012 and 1775 patients were in distant metastasis stages. Intrahepatic cholangiocarcinoma was more invasive and had a higher percentage of metastasis compared with hepatocellular carcinoma. Lung was the most common metastasis and brain was the least common site for both hepatocellular carcinoma and intrahepatic cholangiocarcinoma. Extrahepatic metastasis could consider as an independent prognostic factor for patients with liver cancer. Patients with brain metastasis had the worst prognosis, compared with other metastasis in overall survival (OS) and cancer-specific survival (CSS) analysis.

Conclusions: Different histological subtypes of liver cancer had different metastasis patterns. There were profound differences in risk of mortality among distant extrahepatic metastatic sites. Results from our studies would provide some information for follow-up strategies and future studies.
\end{abstract}

Key words: Neoplasm Metastasis, Liver Neoplasms, SEER Program, Survival analysis

\section{Introduction}

Primary Liver cancer is the sixth common cancer globally, after cancers of the lung, breast, colorectal, prostate and gastric ${ }^{1}$. However, the extremely poor prognosis for primary liver cancer makes it the second leading cause of cancer-related death globally
(745,000 deaths, $9.1 \%$ of the total death $)^{2}$. Despite the prevalence of liver cancer is more frequent in developing country, it is still a significant health burden in many parts of the developed regions, including North America and central Europe ${ }^{3-5}$. In 
contrast to stable or declining trends of other cancers in US (such as lung, breast, and colorectal cancers), the incidence and death rates of primary liver cancer increased rapidly among men and women in recent decades $^{6}$. Unlike hepatitis B viral infection as the predisposing factor for liver cancer in Asian, the increasing incidence in American is largely attributed to infection of chronic hepatitis $\mathrm{C}$ virus $(\mathrm{HCV})^{7}$. Other predominant risk factors included alcohol abuse, non-alcoholic fatty liver diseases (NAFLD), aflatoxin B1 exposure and diabetes mellitus ${ }^{8,9}$. Histologically, the majority of liver cancer is either hepatocellular carcinoma (HCC) or intrahepatic cholangiocarcinoma (ICC), while combined hepatocellular carcinoma and cholangiocarcinoma is less common ${ }^{10}$. Currently, potentially curative therapies for liver cancer include liver transplantation, hepatic resection and radiofrequency ablation. However, these modalities are not readily available to advanced patients ${ }^{11}$. Though these treatments have shown modest improvement in overall survival in early stage disease, the 5-year relative survival for distant metastasis patients is still low (3.1\%). As we all know, primary liver cancer preferentially metastasize to the portal vein and extrahepatic metastasis including lungs, bones, brain, lymph nodes, and adrenal glands ${ }^{12-14}$. Thus far, few detailed studies explored

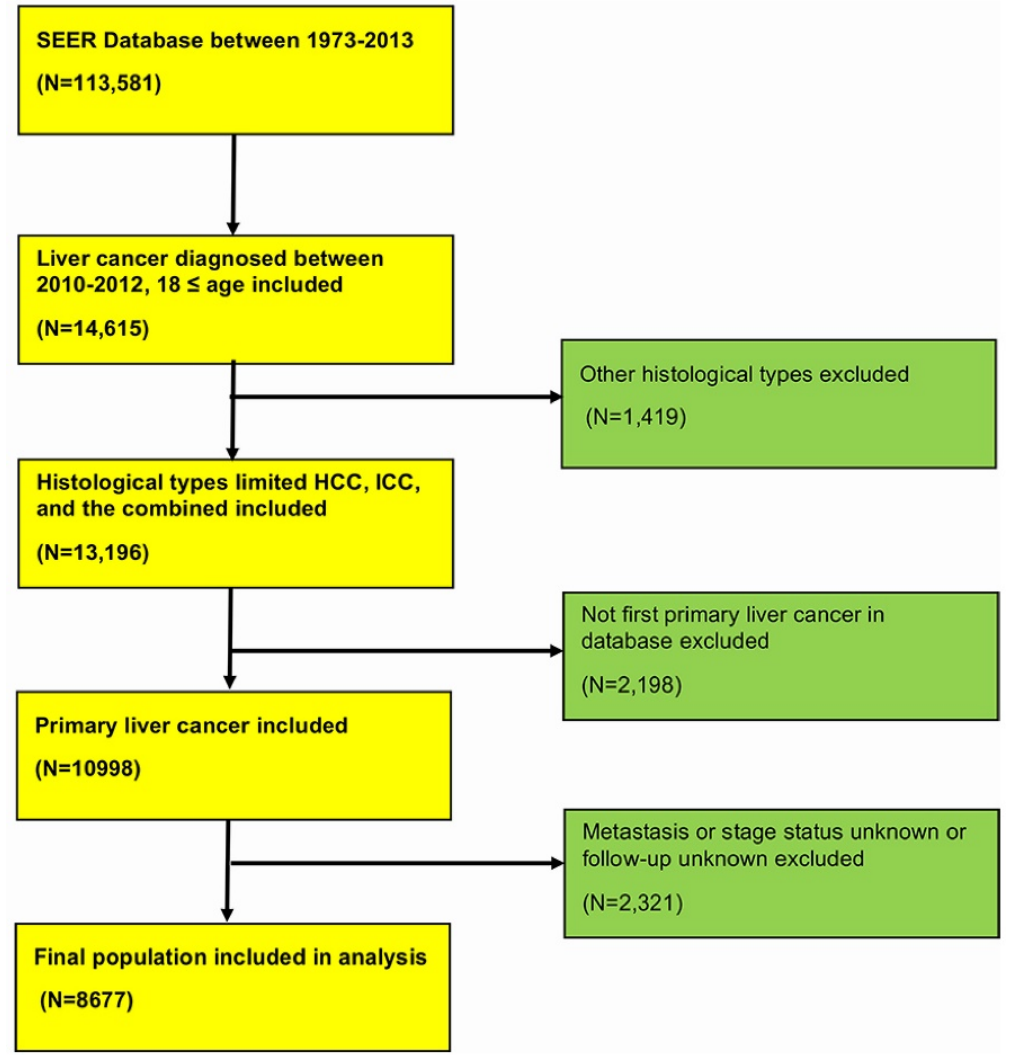

Figure 1. Flowchart of included population in this study. HCC, hepatocellular carcinoma; ICC, intrahepatic cholangiocarcinoma. extrahepatic metastasis profiles due to rare data of liver cancer metastasis. Patterns of extrahepatic metastasis still need further clarification. Besides, it is unclear whether different metastatic sites would be translated into distinct clinical outcomes. Thus, it is crucial to elucidate the metastatic distribution for better treatments and survival benefits. Therefore, in the present study we retrospectively reviewed data from SEER population-based cancer registry, in an attempt to explore metastasis profiles of primary liver cancer. Furthermore, we analysed the clinical characteristics and prognosis according to their distinct metastatic sites. We sought to explore clinical and demographic differences among patients with primary liver cancer.

\section{Methods}

\section{Cohort population}

The Surveillance, Epidemiology, and End Results (SEER) Program is the largest publicly available cancer dataset and is maintained by the National Cancer Institute. The SEER population-based cancer registries contain information from various locations and sources throughout the United States, which represents approximately $28 \%$ of the U.S. population. Data was based on Incidence-SEER 18 Regs Research Data + Hurricane Katrina Impacted Louisiana Cases, Nov 2015 Sub (1973-2013 varying). The detailed population selection procedure was summarized in Figure 1. Briefly, we included patients aged $\geq 18$ years with diagnosis of primary liver cancer between 2010 and 2012 identified from the SEER database. We excluded patients whose metastasis status and follow-up information was unknown. We performed a retrospective cohort study through the SEER database to identify the distant metastasis pattern of primary liver cancer. This database only includes metastasis to the bone, brain, liver, lung and distant lymph nodes at the time of diagnosis since 2010. The study was approved by the review board of the First Affiliated Hospital, School of Medicine, Zhejiang University, Zhejiang, China.

\section{Statistical analysis}

We used descriptive statistics to summary demographic and clinical characteristics of population. Chi-square test and Student's t test were performed to compare categorical and continuous 
variables among different groups of patients, respectively. Overall survival among different metastatic sites was analysed with Kaplan-Meier curves and log-rank test. Furthermore, we performed univariate and multivariate Cox proportional hazards models to identify other variables that might influence the prognosis. Statistical significance was considered at two-sided $\mathrm{P}$ value $<0.05$. All of statistical analyses were performed using statistical software package SPSS 20.0 (SPSS, Inc., Chicago, IL, USA).

\section{Results}

\section{Patients characteristics and metastasis pattern}

From SEER database, we finally identified 8,677 patients who were diagnosed with primary liver cancer from 2010 to 2012. The detailed selection procedure of population was displayed in Figure 1. Primary liver cancer included 7681 hepatocellular carcinomas $(88.5 \%), 986$ intrahepatic cholangiocarcinoma $(11.4 \%), 10$ combined hepatocellular carcinoma and intrahepatic cholangiocarcinoma $(0.1 \%)$. Baseline clinical characteristics of patients were presented in Table 1. As shown in Table 1, there were no significant differences of age, marital status, gender between metastasis and non-metastasis patients. Although intrahepatic cholangiocarcinoma consists a small part of liver cancer, ICC tended to be more likely to distant metastasis compared with HCC (36.4\% vs. $18.4 \%, P<0.01$ ). Patients with advanced stages received less surgery and more radiation therapy.

Among 8677 patients, there were 1775 patients at distant metastasis stages $(20.5 \%)$ when they were diagnosed. Since the SEER only included metastatic site information related to lung, liver, bone, distant lymph and brain at the time of diagnosis, we focused on extrahepatic sites (lung, bone, distant lymph and brain) in further study. Detailed clinical features of extrahepatic metastatic patients were presented in Supplementary Table 1 . The four extrahepatic metastatic sites accounted for $73.2 \%(1300 / 1775)$ of all advanced cases at the time of diagnosis. Lung was the most common metastatic site and brain was least common site, accounting for $36.2 \%(642 / 1775)$ and $1.9 \%$ (34/1775), respectively.

\section{Distant metastasis pattern and combination of metastasis according to histology}

HCC and ICC were different in clinical features, therefore we analysed metastasis patterns according to histological subtypes. Since limited cases of combined HCC and ICC, we did not include this type for our analysis. The detailed clinical information of population with different histological subtypes was shown in Supplementary Table 2. For both HCC and ICC patients, lung and brain were still the most and least frequent extrahepatic metastatic sites, separately (Figure 2). However, several differences in extrahepatic metastatic patterns were existed between histological subtypes. Percentage of lung metastasis ( $38.4 \%$ vs. $27.6 \%, P<0.05)$, bone metastasis $(32.6 \%$ vs. $18.9 \%, P<0.05)$, and distant lymph (24.6\% VS $11.4 \%, P$ $<0.05)$ were higher in HCC patients while there was no difference among incidence rate of brain metastasis between HCC and ICC (Figure 2).

Multiple metastatic sites were found in patients with HCC and ICC. Figure 3 summarizes combinations of metastasis patterns according to histological subtypes. Among HCC, there were no differences among percentages of combinations of lung and any other metastasis site. A similar phenomenon was noted for bone metastasis, combined with any other metastasis site. In ICC patients, lung metastases were always frequently observed in combination with bone metastases and other two combinations (lung and brain, lung and distant lymph) were less common.

Table 1. Baseline clinical characteristics of primary liver cancer patients in SEER database

\begin{tabular}{|c|c|c|c|c|c|}
\hline \multirow[t]{2}{*}{ Characteristic } & \multicolumn{2}{|c|}{ No metastasis } & \multicolumn{2}{|c|}{ Metastasis } & \multirow[t]{2}{*}{$P$ value } \\
\hline & Number & $(\%)$ & Number & $(\%)$ & \\
\hline Age & & & & & 0.333 \\
\hline$<60$ & 2643 & 38.3 & 709 & 39.9 & \\
\hline $60-74$ & 3038 & 44.0 & 773 & 43.5 & \\
\hline$\geq 75$ & 1221 & 17.7 & 293 & 16.5 & \\
\hline \multicolumn{6}{|l|}{ Marital status } \\
\hline Married & 3663 & 53.1 & 891 & 50.2 & 0.080 \\
\hline Unmarried & 2898 & 42.0 & 797 & 44.9 & \\
\hline Unknown & 341 & 4.9 & 87 & 4.9 & \\
\hline Race & & & & & 0.043 \\
\hline White & 4680 & 67.8 & 1236 & 69.6 & \\
\hline Black & 958 & 13.9 & 259 & 14.6 & \\
\hline Other & 1264 & 18.3 & 280 & 15.8 & \\
\hline Gender & & & & & 0.178 \\
\hline Male & 5138 & 74.4 & 1349 & 76.0 & \\
\hline Female & 1764 & 25.6 & 426 & 24.0 & \\
\hline Histology & & & & & $<0.001$ \\
\hline $\mathrm{HCC}+$ & 6269 & 90.8 & 1412 & 79.5 & \\
\hline ICC $\ddagger$ & 627 & 9.1 & 359 & 20.2 & \\
\hline $\begin{array}{l}\text { Combined HCC and } \\
\text { ICC }\end{array}$ & 6 & 0.1 & 4 & 0.2 & \\
\hline Grade & & & & & $<0.001$ \\
\hline High & 1322 & 19.2 & 128 & 7.2 & \\
\hline Moderate & 2050 & 29.7 & 272 & 15.3 & \\
\hline Poor & 881 & 12.8 & 286 & 16.1 & \\
\hline Undifferentiation & 62 & 0.9 & 24 & 1.4 & \\
\hline Unknown & 2587 & 37.5 & 1065 & 60.0 & \\
\hline Surgery therapy & & & & & $<0.001$ \\
\hline Surgery & 2887 & 41.8 & 94 & 5.3 & \\
\hline No surgery & 4001 & 58.0 & 1678 & 94.5 & \\
\hline Unknown & 14 & 0.2 & 3 & 0.2 & \\
\hline Radiation therapy & & & & & $<0.001$ \\
\hline Radiation & 461 & 6.7 & 304 & 17.1 & \\
\hline No Radiation & 6404 & 92.8 & 1465 & 82.5 & \\
\hline Unknown & 37 & 0.5 & 6 & 0.3 & \\
\hline
\end{tabular}

Abbreviation: $\dagger$, HCC, hepatocellular carcinoma; †, ICC, cholangiocarcinoma. 


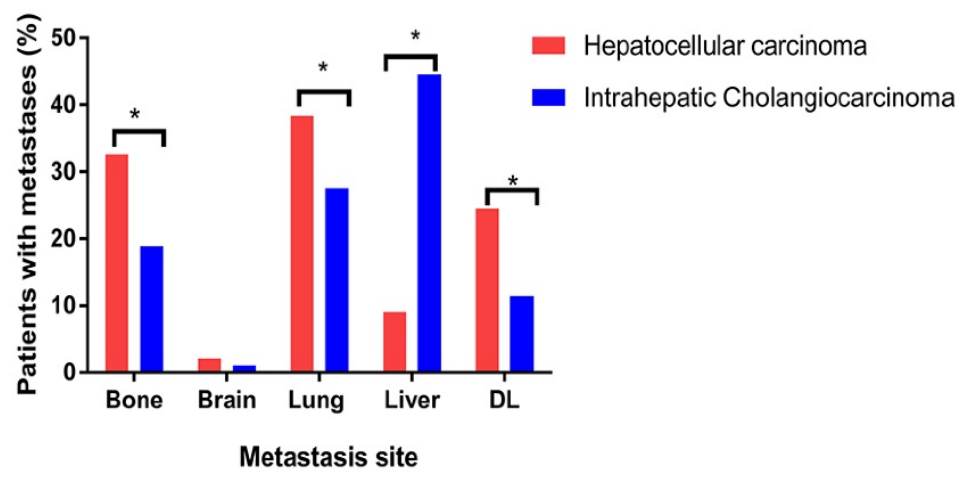

Figure 2. Distribution of distant metastatic sites according to histology (hepatocellular carcinoma and intrahepatic cholangiocarcinoma). DL, distant lymph. $* P<0.05$ (Chi-square test).

A
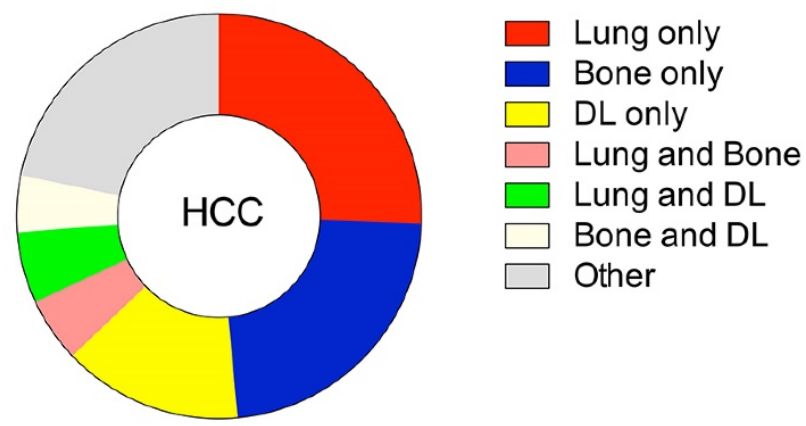

B

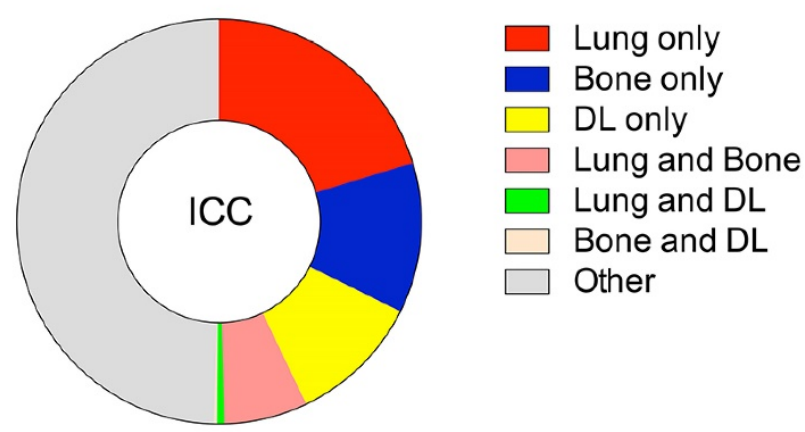

Figure 3. Relative rates of combination-metastatic sites in HCC and ICC. HCC, hepatocellular carcinoma; ICC, intrahepatic cholangiocarcinoma; DL, distant lymph

\section{Survival analysis}

The survival difference associated with distant metastatic sites were illustrated by Figure 4 . Since short duration of follow-up, we estimated the 1-year overall (OS) and cancer-specific survival (CSS) for patients with different extrahepatic metastases in current study. The 1-year OS was $15 \%, 13.7 \%, 10 \%$, $5.9 \%$ for patients with bone, distant lymph, lung, brain metastasis, respectively. The 1-year CSS was $16.5 \%, 14.8 \%, 12.6 \%, 6.3 \%$ for patients with bone, distant lymph, lung, brain metastasis, respectively. Furthermore, we performed univariate and multi- variate Cox regression analysis to identify other variables that might influence the survival. We found that race, gender, age, marital status, histology, grade, and therapies could influence overall survival among patients with liver cancer (Table 2). In addition, different extrahepatic metastatic sites were associated with distant risk of mortality (Table 3). Compared with non-metastasis, patients with brain metastasis had the worst prognosis (OS, HR, 4.12, 95\% CI, 2.92, 5.82; CSS, HR, 4.54, 95\%CI, 3.20, 6.45). and patients with distant lymph metastasis had better survival rate (OS, HR, 2.17, 95\% CI, 1.94, 2.42; CSS, HR, 2.36, 95\% CI, 2.11, 2.64).

Table 2. Univariate and multivariate overall survival analysis of liver cancer in SEER database

\begin{tabular}{|c|c|c|c|c|}
\hline \multirow[t]{2}{*}{ Variable } & \multicolumn{2}{|c|}{ Univariate analysis } & \multicolumn{2}{|c|}{ Multivariate analysis } \\
\hline & $\overline{\mathrm{HR}}{ }^{\prime}(95 \% \mathrm{CI}+)$ & $\mathbf{P}$ & HR (95\% CI) & $\mathbf{P}$ \\
\hline \multicolumn{5}{|l|}{ Race } \\
\hline White & Reference & & Reference & \\
\hline Black & $\begin{array}{l}1.19 \\
(1.11,1.28)\end{array}$ & $<0.001$ & $1.12(1.04,1.21)$ & 0.002 \\
\hline Other & $\begin{array}{l}0.81 \\
(0.75,0.87)\end{array}$ & $<0.001$ & $0.89(0.83,0.96)$ & 0.002 \\
\hline \multicolumn{5}{|l|}{ Gender } \\
\hline Male & Reference & & Reference & \\
\hline Female & $\begin{array}{l}0.93 \\
(0.87,0.98)\end{array}$ & 0.011 & $0.86(0.81,0.92)$ & $<0.001$ \\
\hline \multicolumn{5}{|l|}{ Age } \\
\hline$<60$ & Reference & & Reference & \\
\hline $60-74$ & $\begin{array}{l}1.02 \\
(0.97-1.09)\end{array}$ & 0.434 & $1.02(0.96-1.08)$ & 0.600 \\
\hline$\geq 75$ & $\begin{array}{l}1.45 \\
(1.35-1.56)\end{array}$ & $<0.001$ & $1.29(1.20-1.39)$ & $<0.001$ \\
\hline \multicolumn{5}{|l|}{ Marital status } \\
\hline Married & Reference & & Reference & \\
\hline Unmarried & $\begin{array}{l}1.29 \\
(1.22,1.36)\end{array}$ & $<0.001$ & $1.19(1.13,1.26)$ & 0.000 \\
\hline Unknown & $\begin{array}{l}1.08 \\
(0.96,1.23)\end{array}$ & 0.212 & $1.02(0.89,1.15)$ & 0.820 \\
\hline \multicolumn{5}{|l|}{ Histology } \\
\hline $\mathrm{HCC} \S$ & Reference & & Reference & \\
\hline $\mathrm{ICC} \uparrow$ & $\begin{array}{l}1.37 \\
(1.27,1.48)\end{array}$ & $<0.001$ & $1.28(1.18,1.39)$ & 0.000 \\
\hline $\begin{array}{l}\text { Combined HCC } \\
\text { and ICC }\end{array}$ & $\begin{array}{l}0.71 \\
(0.30,1.71)\end{array}$ & 0.448 & $1.37(0.57,3.30)$ & 0.482 \\
\hline \multicolumn{5}{|l|}{ Grade } \\
\hline High & Reference & & Reference & \\
\hline Moderate & $\begin{array}{l}1.10 \\
(1.00,1.20)\end{array}$ & 0.043 & $1.31(1.20,1.44)$ & $<0.001$ \\
\hline Poor & $\begin{array}{l}1.99 \\
(1.80,2.19)\end{array}$ & $<0.001$ & $2.11(1.91,2.33)$ & $<0.001$ \\
\hline Undifferentiation & $\begin{array}{l}2.38 \\
(1.85,3.05)\end{array}$ & $<0.001$ & $2.69(2.10,3.45)$ & $<0.001$ \\
\hline Unknown & $\begin{array}{l}2.01 \\
(1.85,2.18)\end{array}$ & $<0.001$ & $1.56(1.43,1.69)$ & $<0.001$ \\
\hline \multicolumn{5}{|l|}{ Surgery therapy } \\
\hline Surgery & Reference & & Reference & \\
\hline No surgery & $\begin{array}{l}4.84 \\
(4.51,5.19)\end{array}$ & $<0.001$ & $4.47(4.16,4.81)$ & $<0.001$ \\
\hline Unknown & $\begin{array}{l}5.36 \\
(3.22,8.93)\end{array}$ & $<0.001$ & $4.95(2.97,8.25)$ & $<0.001$ \\
\hline \multicolumn{5}{|l|}{ Radiation therapy } \\
\hline Radiation & Reference & & Reference & \\
\hline No Radiation & $\begin{array}{l}0.89 \\
(0.82,0.97)\end{array}$ & 0.009 & $1.20(1.101 .31)$ & $<0.001$ \\
\hline Unknown & $\begin{array}{l}1.11 \\
(0.77,1.60)\end{array}$ & 0.567 & $0.96(0.67,1.38)$ & 0.837 \\
\hline
\end{tabular}

Abbreviations: $\dagger, \mathrm{HR}$, hazard ratio; $\ddagger, \mathrm{CI}$, confidence interval; $\S, \mathrm{HCC}$,

hepatocellular carcinoma; q, ICC, cholangiocarcinoma. 
A

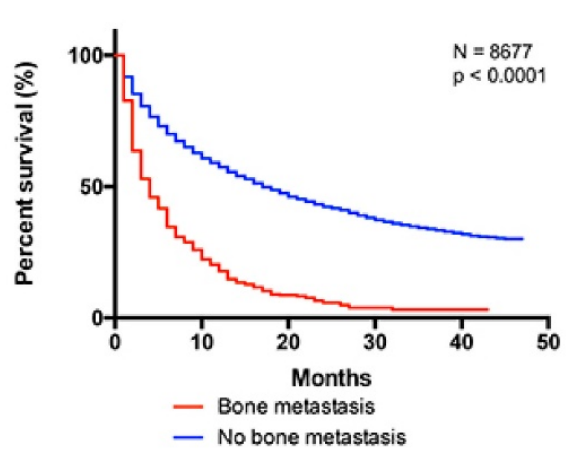

C

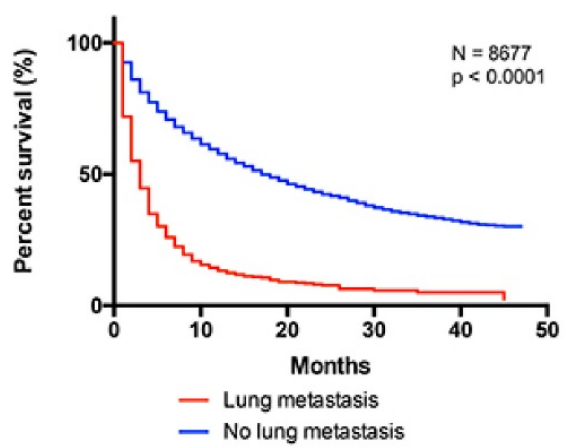

B

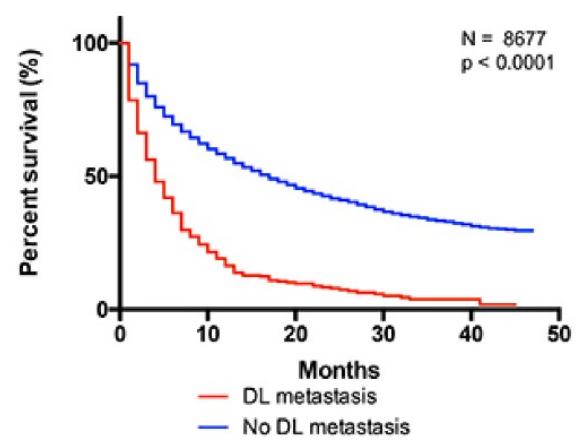

D

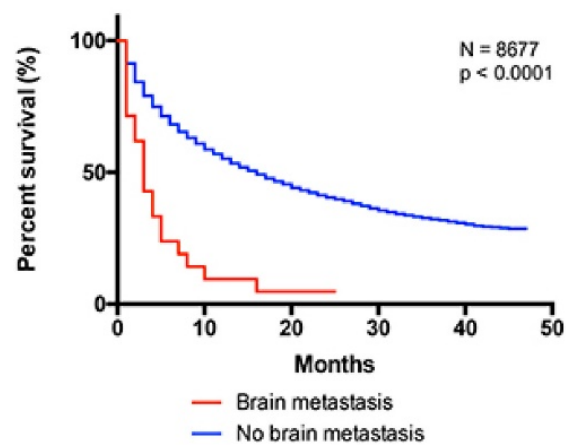

Figure 4. Kaplan-Meier analysis of overall survival in liver cancer patients with and without metastasis. A, with and without bone metastasis (log rank $P<0.0001$ ). B, with and without distant lymph metastasis (log rank $P<0.0001)$. C, with and without lung metastasis $(\log \operatorname{rank} P<0.0001)$. D, with and without brain metastasis (log rank $P<0.0001)$. DL, distant lymph

Table 3. Multivariate analysis of overall and cancer-specific survival in related to metastatic sites

\begin{tabular}{|c|c|c|c|c|}
\hline \multirow[t]{2}{*}{ Variable } & \multicolumn{2}{|l|}{ Overall survival } & \multicolumn{2}{|c|}{ Cancer specific survival } \\
\hline & HR $\dagger(95 \%$ CI $\ddagger) *$ & $\mathbf{P}$ & HR $(95 \% \mathrm{CI}) *$ & $\mathbf{P}$ \\
\hline No metastasis & Reference & & Reference & \\
\hline Lung metastasis & $2.63(2.40,2.88)$ & $<0.001$ & $2.72(2.48,2.99)$ & $<0.001$ \\
\hline Bone metastasis & $2.31(2.09,2.56)$ & $<0.001$ & $2.47(2.22,2.75)$ & $<0.001$ \\
\hline Distant lymph & $2.17(1.94,2.42)$ & $<0.001$ & $2.36(2.11,2.64)$ & $<0.001$ \\
\hline Brain metastasis & $4.12(2.92,5.82)$ & $<0.001$ & $4.54(3.20,6.45)$ & $<0.001$ \\
\hline
\end{tabular}

Table 4. Relationship between metastatic status and survival across liver cancer by race, gender, marital status. (non-metastatic status as reference)

\begin{tabular}{|c|c|c|c|c|}
\hline & \multicolumn{2}{|c|}{$\begin{array}{l}\text { Multivariate analysis } \\
\text { Overall survival }\end{array}$} & \multicolumn{2}{|c|}{$\begin{array}{l}\text { Multivariate analysis } \\
\text { Cancer-specific survival }\end{array}$} \\
\hline & HR† (95\% CI $)$ * & $\mathrm{P}$ & HR $(95 \% \text { CI })^{*}$ & $\mathrm{P}$ \\
\hline \multicolumn{5}{|l|}{ Race } \\
\hline White & $1.24(1.12-1.37)$ & $<0.001$ & $1.20(1.09-1.33)$ & $<0.001$ \\
\hline Black & $1.39(1.14-1.71)$ & 0.001 & $1.33(1.07-1.64)$ & 0.010 \\
\hline Other & $1.26(1.04-1.54)$ & 0.020 & $1.20(0.98-1.47)$ & 0.084 \\
\hline \multicolumn{5}{|l|}{ Gender } \\
\hline Male & $1.26(1.15-1.38)$ & $<0.001$ & $1.21(1.10-1.33)$ & $<0.001$ \\
\hline Female & $1.27(1.08-1.49)$ & 0.004 & $1.24(1.05-1.47)$ & 0.013 \\
\hline \multicolumn{5}{|c|}{ Marital status } \\
\hline Married & $1.21(1.08-1.36)$ & 0.001 & $1.17(1.04-1.32)$ & 0.010 \\
\hline Unmarried & $1.37(1.21-1.55)$ & $<0.001$ & $1.32(1.16-1.50)$ & $<0.001$ \\
\hline
\end{tabular}

*Adjusted for age, grade, therapies.

Abbreviations: $\dagger, \mathrm{HR}$, hazard ratio; $\ddagger, \mathrm{CI}$, confidence interval.

\section{Relationship between metastatic status and survival across liver cancer by race, gender, marital status}

According to previous studies, race, gender, marital status-related discrepancies in prognosis of various cancer had been demonstrated. Therefore, we performed further analysis to examine whether these variables have different effects on association between metastatic status and survival rate. On multivariate overall survival analysis, the Black were found to have a significantly worst prognosis, compared with other racial groups (HR,1.39,95\%1.14-1.71). Female who were under metastatic status have higher risk of mortality compared with male (HR,1.27,95\% 1.08-1.49). Regarding marital status, married patients have better survival than the unmarried (HR,1.37,95\%1.21-1.55). Similar results were found in cancer-specific survival analysis.

\section{Discussion}

Unlike other common cancers with reductions in the incidence and mortality, liver cancer shows unfavourable trends. The prognosis of liver cancer is still poor, particularly for advanced patients with 5-year relative survival rates of $3.1 \% 4$. A clear understanding of clinical features and metastatic sites becomes important essential. With enhanced imaging detection techniques, the reported incidence of 
extrahepatic metastases in patients with liver cancer is increasing. According to previous studies, the common location for extrahepatic metastasis from primary HCC include the lungs, lymph nodes, adrenal glands and bones ${ }^{15-18}$. The most common extrahepatic metastatic site is the lung, which was consistent with our studies. It was firstly reported by Lee et al. ${ }^{13}$ that three leading sites of hepatoma were lung, portal vein, and portal lymph node(s). In 2000, Katyal et al. ${ }^{17}$ reviewed 403 consecutive patients with HCC retrospectively and found that the lung, abdominal lymph nodes, and bone were the main sites of extrahepatic metastatic HCC. They also found that patients with more advanced intrahepatic tumour stage (stage IVA) at the diagnosis were more likely to occur extrahepatic metastases ${ }^{17}$. Another study conducted by Natsuizaka et al. ${ }^{18}$ showed that $73.8 \%$ of extrahepatic metastases patients had intrahepatic liver cancer at stage $\mathrm{T} 3$ or $\mathrm{T} 4$ according to the TNM classification and concluded that the precise evaluation of extrahepatic spread of HCC was crucial for appropriate treatment. However, few studies reported the common extrahepatic metastases for intrahepatic cholangiocarcinoma (ICC). Although the metastasis profile of ICC was similar with HCC, ICC showed a more invasive biological characteristic according to our studies. A better understanding of potential sites and clinical features of extrahepatic metastases may be crucial to determine appropriate therapies, which ultimately influence patients' survival.

In the present study, we found that lung was the most common extrahepatic site for both HCC and ICC, followed by bone, distant lymph and brain. The main metastatic site of ICC is liver, whereas HCC was significantly more frequent to develop lung and bone metastasis than ICC. This suggested that we should pay more attention to extrahepatic metastasis of HCC patients. Furthermore, we analysed the survival rate and found that race, gender, age, marital status, histology, grade, and therapies were all significantly associated with OS. Besides, different extrahepatic metastatic sites also influenced overall and cancer-specific mortality. Sufficient treatments of both surgery and radiation therapies may improve prognosis even in advanced stage patients ${ }^{19}, 20$. Survival rate for patient with brain metastasis was worse than patients with bone metastasis. Hence, the presence of brain metastasis was an indicator of poor survival for primary liver cancer, although it was rare. Understanding of different extrahepatic metastatic sites was important for clinicians to adopt appropriate treatment choices. Furthermore, we observed that the Black, female, and unmarried patients had higher risk of mortality. Our study confirmed the association between biologic impacts with variables on prognosis of liver cancer, although the details are remains unclear).

To our knowledge, this is the first large population-based study from SEER to explore the extrahepatic metastasis of HCC and ICC, considering them as separate entities. We summarized metastatic patterns of HCC and ICC and analysed the impact of metastasis disparity on survival of liver cancer patients. However, several potential limitations of our study should be considered. First, it is important to note that we only included synchronous extrahepatic metastasis information. Some patients who would develop metachronous metastasis lesions were not included in our study, which might lead to underestimate extrahepatic metastasis of liver cancer. Furthermore, the database only provided limited metastatic sites but other extrahepatic metastatic sites (such as adrenal glands, peritoneum) were unclear. However, as we have noted, these four metastasis sites accounted for $73.2 \%$ of advanced liver cancer patients. Lastly, data related to chemotherapy was not available from SEER, which might influence survival analysis.

In conclusion, we found that both HCC and ICC patients present with similar extrahepatic metastatic patterns (lung, followed by bone, distant lymph and brain metastasis). Patients with distant lymph metastasis enjoyed best survival outcomes while patients with brain metastasis owned the worst prognosis in both OS and CSS analysis.

\section{Supplementary Material}

Supplementary tables.

http://www.jcancer.org/v08p2312s1.pdf

\section{Acknowledgements}

The authors acknowledge the efforts of the SEER Program cancer registries in the creation of the SEER database.

The work was funded by the Key Program of the National Natural Science Foundation of China (No. 81330011) and Science Fund for Creative Research Groups of the National Natural Science Foundation of China (No.: 81121002).

\section{Competing Interests}

The authors have declared that no competing interests exist.

\section{References}

[1] Torre LA, Bray F, Siegel RL, Ferlay J, Lortet-Tieulent J, Jemal A. Global cancer statistics, 2012. CA Cancer J Clin. 2015; 65: 87-108.

[2] Ferlay J, Soerjomataram I, Dikshit R, et al. Cancer incidence and mortality worldwide: sources, methods and major patterns in GLOBOCAN 2012. Int J Cancer. 2015; 136: E359-86. 
[3] Bosetti C, Levi F, Boffetta P, Lucchini F, Negri E, La Vecchia C. Trends in mortality from hepatocellular carcinoma in Europe, 1980-2004. Hepatology. 2008; 48: 137-45.

[4] Ryerson AB, Eheman CR, Altekruse SF, et al. Annual Report to the Nation on the Status of Cancer, 1975-2012, featuring the increasing incidence of liver cancer. Cancer. 2016; 122: 1312-37.

[5] Hashim D, Boffetta P, La Vecchia C, et al. The global decrease in cancer mortality: trends and disparities. Ann Oncol. 2016; 27: 926-33.

[6] Siegel RL, Miller KD, Jemal A. Cancer statistics, 2016. CA Cancer J Clin. 2016; 66: 7-30

[7] Perz JF, Armstrong GL, Farrington LA, Hutin YJ, Bell BP. The contributions of hepatitis $B$ virus and hepatitis $C$ virus infections to cirrhosis and primary liver cancer worldwide. J Hepatol. 2006; 45: 529-38.

[8] Makarova-Rusher OV, Altekruse SF, McNeel TS, et al. Population attributable fractions of risk factors for hepatocellular carcinoma in the United States. Cancer. 2016; 122: 1757-65.

[9] Welzel TM, Graubard BI, Quraishi S, et al. Population-attributable fractions of risk factors for hepatocellular carcinoma in the United States. Am J Gastroenterol. 2013; 108: 1314-21.

[10] Tang D, Nagano H, Nakamura M, et al. Clinical and pathological features of Allen's type $\mathrm{C}$ classification of resected combined hepatocellular and cholangiocarcinoma: a comparative study with hepatocellular carcinoma and cholangiocellular carcinoma. J Gastrointest Surg. 2006; 10: 987-98.

[11] Njei B, Rotman Y, Ditah I, Lim JK. Emerging trends in hepatocellular carcinoma incidence and mortality. Hepatology. 2015; 61: 191-9.

[12] Olubuyide IO. Pattern of metastasis of primary liver cancer at autopsy: an African series. Trop Gastroenterol. 1991; 12: 67-72

[13] Lee YT, Geer DA. Primary liver cancer: pattern of metastasis. J Surg Oncol. 1987; 36: 26-31.

[14] Jiang XB, Ke C, Zhang GH, et al. Brain metastases from hepatocellular carcinoma: clinical features and prognostic factors. BMC Cancer. 2012; 12: 49.

[15] Sawabe M, Nakamura T, Kanno J, Kasuga T. Analysis of morphological factors of hepatocellular carcinoma in 98 autopsy cases with respect to pulmonary metastasis. Acta Pathol Jpn. 1987; 37: 1389-404.

[16] Uchino K, Tateishi R, Shiina S, et al. Hepatocellular carcinoma with extrahepatic metastasis: clinical features and prognostic factors. Cancer. 2011; 117: 4475-83.

[17] Katyal S, Oliver JH, 3rd, Peterson MS, Ferris JV, Carr BS, Baron RL. Extrahepatic metastases of hepatocellular carcinoma. Radiology. 2000; 216: 698-703.

[18] Natsuizaka M, Omura T, Akaike T, et al. Clinical features of hepatocellular carcinoma with extrahepatic metastases. J Gastroenterol Hepatol. 2005; 20: 1781-7.

[19] Belghiti J, Kianmanesh R. Surgical treatment of hepatocellular carcinoma. HPB (Oxford). 2005; 7: 42-9.

[20] Klein J, Dawson LA. Hepatocellular carcinoma radiation therapy: review of evidence and future opportunities. Int J Radiat Oncol Biol Phys. 2013; 87: 22-32. 